\title{
Os atlas linguísticos brasileiros e o inquiridor: em busca de uma metodologia adequada
}

\author{
Greize Alves da SILVA * \\ Vanderci de Andrade AGUILERA **
}

Resumo: Neste artigo, iniciando uma discussão sobre os procedimentos metodológicos da Geolinguística no Brasil, apresentamos uma reflexão a respeito da constituição da equipe de pesquisadores de campo e sua importância para pesquisas desta natureza. Para tal, buscamos a metodologia adotada pelos nove atlas estaduais brasileiros concluídos no período de 1963 a 2008 no que se refere à composição da equipe de investigadores/ inquiridores de campo. Ao final, analisamos a equipe do Projeto Atlas Linguístico do Brasil, comparando-a às equipes dos atlas estaduais, salientando seus aspectos convergentes e divergentes.

Palavras-chave: Atlas linguísticos brasileiros; Equipe de inquiridores; Projeto Atlas Linguístico do Brasil.

\begin{abstract}
In this paper, starting a discussion about methodological procedures of Geolinguistics in Brazil, we present a reflection on the formation of a field research team and its importance for research of this kind. We therefore identify the methodology adopted by nine Brazilian State atlases produced from 1963 to 2008 , in regard to the composition of their teams of field researchers/inquirers. Finally, we analyse the composition of the
\end{abstract}

\footnotetext{
* Mestranda em Estudos da Linguagem da Universidade Estadual de Londrina. Contato: greize_silva@yahoo.com.br.

** Doutora em Letras pela Universidade Estadual Paulista Julio de Mesquita Filho - Assis (1990). Docente da Universidade Estadual de Londrina. Contato: vanderci.aguilera@terra.com.br.
} 
team of the Brazil Linguistic Atlas Project, and compare it with the teams of the State atlases, whereby we enhance both their convergent and divergent aspects.

Keywords: Brazilian linguistics atlases; Team of inquires; Brazil Linguistic Atlas Project.

\section{Apresentação}

Identificar e descrever fatos referentes à própria língua e à língua utilizada por diferentes povos não são prerrogativas de nossos tempos. Sabemos que há pelo menos dois séculos, no mundo ocidental os estudiosos se voltavam para este tema, buscando métodos e técnicas que pudessem dar uma resposta mais satisfatória à sua curiosidade. Constituída sob o tríplice aspecto: sociedade, cultura e história, a língua reflete as modificações ocorridas durante séculos com a humanidade e por meio dela se conhece a história de uma civilização em toda a sua completude.

Com a finalidade de contribuir para o entendimento de uma língua como instrumento social de comunicação diversificado, os atlas linguísticos normalmente abarcam vários elementos constituintes de uma língua, dentre eles o lexical, o fonético e o morfossintático e os dispõem em forma de cartas linguísticas como depositário histórico dos vários falares presentes em dada localidade.

Dessa forma, no Brasil, na década de 50, embora com um atraso de quase meio século em relação ao Atlas Linguistique de la France, já se falava da necessidade de o Brasil ter um atlas nacional (SILVA NETO, 1957; NASCENTES, 1958; 1961).

Fatores diversos impediam que a ideia vingasse: a extensão territorial, a escassez de recursos financeiros, malha viária (rodoviária, ferroviária e aérea) deficitária e inadequada, tudo isso agravado pela falta de uma mentalidade acadêmica voltada aos estudos dialetológicos. A propósito desse fato, Nascentes (1958, p. 7), grande defensor da necessidade de um atlas brasileiro, relata que, em 1954, o professor Sever Pop veio a convite ministrar um curso de Dialetologia; porém os resultados não foram os esperados, 
pois não houve interesse por parte da platéia masculina e, segundo o autor, as mulheres não estariam aptas para a grande empreitada, devido às grandes distâncias a serem percorridas.

Diante de tais dificuldades, estudiosos da língua dedicaramse a publicar obras de suporte metodológico para a elaboração de um futuro atlas. É o caso do próprio Nascentes que, nas Bases para a Elaboração do Atlas Linguístico do Brasil (v. 1, 1958; v. 2, 1961), sugere que se faça como os Estados Unidos, que

[...] país vasto e rico, com excelentes estradas, entregou-se à elaboração de atlas regionais, para mais tarde juntá-lo no atlas geral. Assim também devemos fazer em nosso país, que é também vasto e, ainda mais, pobre e sem fáceis vias de comunicação. (NASCENTES, 1958, p. 7)

Não só no Brasil, mas também em outros países, pesquisadores como Alvar, autor de várias obras de caráter multidialetal, dentre elas o Atlas Linguístico de Andalucia (ALEA), defendem a ideia da elaboração de atlas menores ou regionais. Para Alvar é inegável a importância dos atlas regionais como "testimonio dialetal" (ALVAR, 1969, p. 127) e que, por meio dessas obras,

[...] tienen enormes ventajas: conocimiento depurado de las áreas que se estudian, penetración en las estructuras linguísticas más recónditas, establecimiento seguro de isoglosas, exacta correspondencia entre las cuestiones formuladas y las respuestas obtenidas. El gran inconveniente de estas obras es que no cobran sentido sino en el conjunto. (ALVAR, 1969, p. 198) ${ }^{1}$

\footnotetext{
${ }^{1}[\ldots]$ têm enormes vantagens: conhecimento apurado das áreas que se estudam, penetração nas estruturas linguísticas mais recônditas, estabelecimento seguro de isoglossas, exata correspondência entre as questões formuladas e as respostas obtidas. O grande inconveniente dessas obras é que não adquirem sentido, a não ser no conjunto.
} 
Dessa forma, no Brasil, entre 1963 e 2008, são apresentados à comunidade científica nove ${ }^{2}$ atlas estaduais que, embora não tenham sido elaborados a partir da mesma metodologia e sob uma única orientação, representam: (i) o avanço dos estudos dialetológicos do Brasil; (ii) a disseminação das ideias geolinguísticas pelos vários estados da União; e (iii) a consequente criação de numerosos núcleos de pesquisadores, como a UNESP, a UEL, a UFMS, a UFPA e a UFAM, situados fora dos tradicionais centros de estudos dialetológicos como a UFBA, a UFRJ e a UFRGS.

Essas nove obras seguem os procedimentos metodológicos tradicionais como explicitados por Brandão (1991, p. 25-39): (i) levantamento preliminar dos dados; (ii) fixação dos pontos de inquérito; (iii) seleção dos informantes; (iv) técnica de escolha de dados (elaboração de um questionário); (v) aplicação dos inquéritos; (vi) catalogação, armazenamento e transcrições dos dados e (vii) preparo das cartas.

Analisando as obras de geolinguística que tratam da metodologia, neste artigo apresentamos uma reflexão a respeito da constituição da equipe de pesquisadores de campo e sua importância para pesquisas desta natureza. Para tal propósito, dividimos este estudo nos seguintes passos: (i) conceito de pesquisador de campo e denominações que lhe são atribuídas; (ii) perfil do pesquisador de campo e tempo de recolha dos dados; (iii) composição da equipe dos diversos atlas estaduais e regional brasileiros; e (iv) constituição da equipe do ALiB.

$\mathrm{O}$ corpus está formado pelos dados referentes à metodologia adotada, no que se refere ao inquiridor, pelos atlas regionais publicados até o presente momento no Brasil: Atlas Prévio dos Falares

\footnotetext{
${ }^{2} \mathrm{Na}$ realidade, são onze atlas concluídos se incluirmos nesta lista o Atlas Lingüístico de Sergipe II (CARDOSO, 2005) e o Atlas Lingüístico do Paraná II (ALTINO, 2007), elaborados a partir dos dados que não haviam sido cartografados nos atlas originais. Ambos seguem, portanto, a mesma metodologia do respectivo volume anterior.
} 
Baianos (ROSSI, 1963); Esboco de um Atlas Lingüístico de Minas Gerais (RIBEIRO et al., 1977); Atlas Lingüistico da Paraíba (ARAGÃO; MENEZES, 1984); Atlas Linguiistico de Sergipe (FERREIRA et al., 1987); Atlas Lingüistico do Paraná (AGUILERA, 1994); Atlas Lingüístico-Etnográfico da Região Sul (KOCH; KLASSMANN; ALTENHOFEN, 2002); Atlas Lingüístico do Amazonas (CRUZ, 2004); Atlas Lingüistico Sonoro do Pará (RAZKY, 2004); Atlas Lingüistico de Sergipe II (CARDOSO, 2005); Atlas Lingüístico do Paraná II (ALTINO, 2007) e Atlas Lingüistico do Mato Grosso do Sul (OLIVEIRA, 2008). Ao final, tratamos da composição da equipe de pesquisadores de campo do Projeto Atlas Linguístico do Brasil.

1 Conceito de pesquisador de campo e denominações que lhe são atribuídas

Para Mouton (1996, p. 65), o pesquisador de campo, por ela denominado encuestador, é o "investigador preparado para elegir informante, preguntarle adecuadamente el cuestionario y transcribir sus respuestas". ${ }^{3}$ A autora deixa claro que se trata de alguém preparado para tal mister, não um leigo, ou amador.

Quanto às denominações, as obras de Dialetologia e Geolinguística consultadas atribuem nomes diferentes ao pesquisador de campo, tais como: dialetólogo e investigador (VENY, 1986, p. 98); inquiridore pesquisador (PROJETO ALiB); documentador, documentador especialista, exploradore coletor (ALVAR, 1969); investigador (CINTRA, 1995, p. 26); explorador e investigador denominações atribuídas a Edmond Edmont, colaborador de Gilliéron na elaboração do ALF (IORDAN, 1982, p. 205).

A terminologia mais utilizada, porém, refere-se a inquiridor ou investigador, embora haja controvérsias na utilização dessas

3 ... investigador preparado para escolher informante, perguntar-lhe adequadamente o questionário e transcrever suas respostas. Um atlas pode contar com mais de um entrevistador, sempre que a equipe for homogênea. (tradução nossa) 
denominações por soarem inadequadas, politicamente incorretas para alguns puristas, por lembrarem ações policiais da época da ditadura militar que, felizmente, já superamos em todos os sentidos.

A geolinguística, porém, vem resgatar o significado original de inquiridor: aquele que inquire (FERREIRA, 2004), deixando de lado o sentido antigo, ultrapassado, de oficial de justiça que inquiria testemunhas, conforme consta do dicionário Aurélio. Inquirir, no mesmo dicionário, tem como primeira acepção: procurar informações acerca de; indagar; investigar; pesquisar.

Ainda citando Mouton (1996), no excerto exemplificado, ao pesquisador cabem múltiplas tarefas: a de selecionador de informantes, de investigador de campo e de transcritor das entrevistas.

Nos início das pesquisas geolinguísticas, quando não se contava com o auxílio de aparelhos gravadores de áudio, era imprescindível que o inquiridor também dominasse as técnicas de transcrição fonética, que se dava simultaneamente à aplicação do questionário. Essa forma de transcrição in loco e simultânea ocorreu com o Atlas Linguistique de la France, de Gilliéron, que contou com a total participação de Edmond Edmont nas três etapas: a de selecionador de informantes, a de investigador de campo e a de transcritor das entrevistas.

Da mesma forma, no Brasil, o primeiro atlas publicado, Atlas Prévio dos Falares Baianos, também contou com a coleta e transcrição in loco, sendo necessário que, em cada entrevista, participassem pelo menos dois pesquisadores, pois, enquanto um arguia, o outro transcrevia foneticamente os dados. Os demais atlas já puderam contar com aparelhos gravadores de som, de várias marcas e dimensões, desde os grandes e pesados gravadores até os quase imperceptíveis MP3.

\section{$2 \mathrm{O}$ número e o perfil do inquiridor e o tempo gasto na coleta dos dados}

Quanto à formação ou perfil do pesquisador de campo, esta discussão confunde-se com a própria fundação da Geografia Linguística: a necessidade de o inquiridor ser ou não um linguista. 
Para Gilliéron, segundo Alvar (1969), o pesquisador deve reunir alguns requisitos, como: ter bom relacionamento interpessoal, ter gosto pelos fenômenos dialetais, porém, ser leigo em Linguística e Filologia, pois, do contrário, o resultado da pesquisa poderia ser prejudicado.

Em contrapartida, quando Gilliéron escolheu Edmont para a coleta do ALF, sabia do interesse deste inquiridor pelos fenômenos da língua e da facilidade dele para ouvir e transcrever os dados. Diante desta aptidão de Edmont, pergunta-se: até que ponto ele pode ou não ser considerado linguista, uma vez que já tinha realizado outros trabalhos dialetológicos, tal como o Léxico de Saint-Pol-Sur? (VENY, 1986, p. 97)

Sobre o fato de o inquiridor não ter conhecimentos de Linguística, outros autores discordam dessa atitude. Wouk (1981), por exemplo, cita que a pesquisa dialetológica obtém maior êxito quando o inquiridor sabe o que está sendo buscado. Nesse particular, os atlas regionais comprovam a hipótese de Wouk, pois todos os atlas regionais brasileiros foram coordenados por especialistas em Dialetologia e auxiliados por estudantes de Letras devidamente preparados para essa tarefa.

Um dos problemas que mais afligem o dialetólogo é o tempo despendido na recolha dos dados. Se a coleta de todo o material levar muito tempo, corre-se o risco dos resultados apresentarem, muitas vezes, fatos diacrônicos e não sincrônicos. Ainda paralelamente ao tempo gasto na pesquisa, esbarra-se na também discutida questão da quantidade de inquiridores.

O próprio Gilliéron era inimigo da pluralidade de coletores, acreditando que, dessa forma, a homogeneidade do trabalho seria prejudicada. Por isso, Edmont coletou os dados em $639^{4}$ localidades francesas, durante cerca de quatro anos, tempo muitíssimo curto para a densidade da rede de pontos do ALF.

\footnotetext{
${ }^{4}$ Brandão (1991, p. 10) e Iordan (1982, p. 204) falam em 639 localidades e Veny traz 649 (1986, p. 98).
} 
Segundo Veny (1986, p. 98), posteriormente, dialetólogos, como Griera, autor do ALC (Atlas da Catalunha) e Bottiglioni, autor do ALEC (da Córsega), também em seus projetos iniciais realizaram eles próprios a coleta para os respectivos atlas. Porém, quando se tratava de atlas de grandes domínios ou extensões territoriais, para não prolongar o tempo da coleta, o diretor do atlas incorporava vários investigadores, como ocorreu com Jud, para o atlas ítalo-suíço (AIS) e Navarro Tomás, da Península Ibérica (ALPI).

Inicialmente, Alvar (1991, p. 221), buscando compor uma amostra mais homogênea para o Atlas Linguístico de Andalucia, cogitou a possibilidade de ele próprio colher os dados em 225 localidades que, em seus cálculos, levaria aproximadamente dez anos. Esse cálculo levou-o a incorporar dois alunos à sua pesquisa, explicando:

[...] A mí, como director de un Atlas - ante el problema de la pluralidad de exploradores. Mi primitiva idea - colector único - hubo de ser desechada. La necesidad exigió llegar hasta ese número tres, que me parece muy poco excesivo. ${ }^{5}$

\section{Formação da equipe de investigadores nos atlas estaduais brasileiros}

No Brasil, no que se refere aos atlas estaduais publicados, na ausência de uma coordenação central para a elaboração de metodologia única para os atlas regionais, cada equipe adotou procedimentos próprios para todas as etapas da realização do atlas, inclusive na composição da equipe de inquiridores.

\footnotetext{
${ }^{5}$ A mim, como diretor de um Atlas - diante do problema da pluralidade de pesquisadores. Minha primeira ideia - coletor único - teve que ser descartada. A necessidade exigiu chegar até o número de três, que me parece muito pouco excessivo. (tradução nossa)
} 
O Atlas Prévio dos Falares Baianos (APFB), por exemplo, primeiro atlas publicado no Brasil e coordenado por Nelson Rossi, para uma rede de pontos constituída por 50 localidades, ${ }^{6}$ contou com a participação de nove inquiridores devidamente preparados para atuarem como pesquisadores de campo. Os inquéritos foram iniciados em 1960 e concluídos em abril de 1961. O Quadro 1 apresenta a relação dos inquiridores e os pontos em que cada qual atuou.

\begin{tabular}{|l|l|l|}
\hline \hline INQUIRIDORES & PONTOS & Total \\
\hline Anna Maria Martins Garcia & $1,2,3,4,5,6,7,8,9,10,11,12,24,33$, & 19 \\
& $34,35,36,42,43$ & \\
\hline $\begin{array}{l}\text { Dinah Maria Montenegro } \\
\text { Isensee }\end{array}$ & $\begin{array}{l}4,5,7,8,9,10,11,12,24,28,30,32, \\
33,34,35,36,42,43\end{array}$ & 18 \\
\hline $\begin{array}{l}\text { Judith Mendes de Aguiar } \\
\text { Freitas }\end{array}$ & $\begin{array}{l}1,2,5,6,13,14,15,16,17,16,19,26, \\
27\end{array}$ & 13 \\
\hline Carlota da Silva Ferreira & $3,5,28,30,31,32,37,38,39,40,41,50$ & 12 \\
\hline Josefina Barleta & $5,6,13,14,15,16,17,19,29$ & 9 \\
\hline Cyra Ribeiro de Sá Leite & $3,5,18,20,21,22,23,25,29$ & 9 \\
\hline Tânia Meirelles Pedrosa & $3,5,18,31,37,38,39,40,41$ & 9 \\
\hline Nelson Rossi & $5,26,27,44,45,46,47,48,49$ & 9 \\
\hline $\begin{array}{l}\text { Edelweiss Yêda d'Almeida } \\
\text { Nunes }\end{array}$ & $5,20,21,22,23,25$ & 6 \\
\hline
\end{tabular}

Fonte: ROSSI (1963, p. XI)

Quadro 1 - Inquiridores do APFB

É importante lembrar que, em cada inquérito, atuaram pelo menos dois entrevistadores, conforme demonstra o Quadro 1. O número de informantes por localidade, no $\mathrm{APFB}$, não é homogêneo, variando entre um por localidade até seis em outra,

\footnotetext{
${ }^{6}$ Nascentes $(1958,1961)$ faz uma relação das localidades brasileiras que deveriam compor o Atlas Linguístico do Brasil. Dessa forma, o autor propõe para o estado da Bahia o número de 39, localidades, das quais foram aproveitadas pelo APFB 13 pontos.
} 
embora na maioria dos pontos fossem entrevistados dois informantes. Quanto à atuação dos inquiridores, também não há uma distribuição equitativa, pois o número de inquéritos por inquiridor oscila entre 6 e 19.

Em 1963, outra equipe foi constituída, também sob a coordenação de Nelson Rossi, para a realização de um estudo preliminar no estado de Sergipe, que mais tarde daria origem ao atlas linguístico desse Estado. A rede foi composta por 15 localidades ${ }^{7}$ e os dados foram coletados entre 1966 e 1967. Dessa pesquisa participaram cinco inquiridores de campo, dois dos quais já haviam integrado a equipe do APFB: o autor, Nelson Rossi, e Carlota Ferreira, co-autora do ALS (1987).

Os inquiridores sempre atuaram aos pares, embora a entrevista agora fosse gravada, possibilitando a transcrição posterior dos dados. A tecnologia dos gravadores de áudio, iniciante em nosso país, embora fossem aparelhos grandes e pesados, permitiu um avanço nos estudos geolinguísticos, devido à possibilidade de voltar aos dados para corrigir eventuais erros de transcrição ou de audição dos registros dos informantes. Sobre o assunto, Rossi comenta (FERREIRA et al., Notas Preliminares, iii):

O registro magnetofônico integral de todos os inquéritos soma para Sergipe cerca de 150 horas, constituindo, portanto, uma documentação muito mais abundante, mais segura, rigorosa e sistemática do que aquela que pudemos lançar mão para as cartas do APFB.

\footnotetext{
${ }^{7}$ Inicialmente, Nascentes (1958) sugere 16 pontos para Sergipe, das quais os autores do ALS aproveitaram sete delas.
} 


\begin{tabular}{||l|l|l|l|}
\hline \multirow{2}{*}{ INQUIRIDORES } & \multicolumn{2}{|l|}{ INQUÉRITOS } & T \\
\cline { 2 - 4 } & Feminino & Masculino & \\
\hline Nelson Rossi & 0 & $\begin{array}{l}52,54,55,58,60,63, \\
64,65\end{array}$ & 8 \\
\hline Carlota Ferreira & 56,59 & $51,53,57,61,62$ & 7 \\
\hline Jacyra Mota & $57,61,62$ & 56,59 & 5 \\
\hline Nadja Andrade & $52,54,55,58,60$ & 0 & 5 \\
\hline Suzana A. Cardoso & $51,53,63,64,65$ & 0 & 5 \\
\hline
\end{tabular}

Fonte: CARDOSO (2005, p. 21)

Quadro 2 - Inquiridores do ALS, por sexo F ou M

Cada entrevistador inquiriu em média seis informantes, mas um dado chama a atenção, no Quadro 2: Rossi inquiriu em Sergipe apenas informantes masculinos, enquanto Andrade e Cardoso inquiriram as femininas. Deduz-se que acreditavam que os informantes poderiam sentir-se mais à vontade com inquiridores do mesmo sexo. Trata-se de um procedimento que merece ser observado em pesquisas futuras, para que se possa certificar se os resultados variam conforme o sexo ou gênero dos envolvidos na coleta de dados.

Relativamente ao Esboço do Atlas Lingüístico de Minas Gerais (EALMG), a coleta dos dados iniciou-se em 1970 e foi concluída em 1976. Com uma rede de pontos compatível com a densidade demográfica do Estado de Minas Gerais: 116 localidades, ${ }^{8}$ contou com quatro inquiridores principais.

O Quadro 3 permite visualizar a produtividade de cada um desses inquiridores.

${ }^{8}$ Zágari (2005, p. 47) registra 184 pontos, mas do volume 1 constam os registros dos 116 primeiros pontos. 


\begin{tabular}{|l|l|l|}
\hline INQUIRIDORES & PONTOS & T \\
\hline Mario Roberto & 2a, 3a/b/c, 4a, 5a/b/c, 7a, 12, 13, 24, 25, 26, 28, 29, 30, & 44 \\
& $31,32,33,34,36,37,40,4142,43,44,46,47,54,55,56$, & \\
& $57,58,72,73,74,82,87,88,96,98,101$. & \\
\hline Zágari & $1,5,6 \mathrm{a} / \mathrm{b} / \mathrm{c}, 9,16,17,25,27,28,29,45,47,51,52,53$, & 38 \\
& $59,61,63,64,65,68,69,70,71,76,77,78,79,80,83,84$, & \\
& $85,86,97,98,99$. & \\
\hline José Ribeiro Passini & $2 \mathrm{a}, 3 \mathrm{a} / \mathrm{b} / \mathrm{c}, 5 \mathrm{a} / \mathrm{b} / \mathrm{c}, 6,7,8,10,12,13,21,23,16,17,18$, & 37 \\
& $30,31,32,34,36,37,41,43,44,46,53,58,59,64,65,69$, & \\
& $46,77,90$. & \\
\hline Antonio Perez Gaio & $1 \mathrm{a} / \mathrm{b} / \mathrm{c}, 2,3,4 \mathrm{a}, 11,14,15,19,20,21,22,35,38,39,48$, & 31 \\
& $49,50,60,62,66,67,81,87,89,92,93,94,95,100$ & \\
\hline José Dion Ladeira & 75,91 & 2 \\
\hline Jonas Magal Gomes & 4 & 1 \\
\hline
\end{tabular}

Fonte: EALMG (RIBEIRO et al., 1977, carta Inquiridores)

Quadro 3 - Inquiridores do EALMG

Verifica-se, pelo Quadro 3, o número reduzido de entrevistadores, praticamente quatro, excluindo-se Gomes e Ladeira, que fizeram, respectivamente, uma e duas entrevistas. Em algumas localidades atuaram de dois a três entrevistadores, como se observa nos pontos $3 \mathrm{a}, 3 \mathrm{~b}$ e $3 \mathrm{c}, 5 \mathrm{a}, 5 \mathrm{~b}$ e $5 \mathrm{c}$. A coleta dos dados durou em média seis anos, principalmente porque, no início, todos os gastos referentes à pesquisa eram por conta dos pesquisadores (RIBEIRO et al., 1977, p. 20), o que dificultou ainda mais a recolha do material. Segundo os autores, a ideia de inquiridor único não chegou nem a ser cogitada pela equipe, sendo considerada inviável e antieconômica.

O EALMG apresenta uma peculiaridade em relação aos demais Atlas estaduais já publicados no Brasil: além da coleta inloco, realizou a pesquisa indireta, ${ }^{9}$ ou seja, foram enviados

\footnotetext{
${ }^{9}$ A pesquisa indireta já havia sido realizada por um dos precursores da geolinguística na Alemanha. Wenker em 1876 iniciou seu trabalho de coleta no território alemão, enviando questionários por correspondência para 50.000 informantes, solicitando que apontassem a pronúncia local em 40 frases por ele selecionadas.
} 
questionários para 672 localidades e obtidas 409 respostas. Segundo os autores, este recurso foi utilizado no EALMG com a finalidade de controlar respostas dadas pelos informantes na pesquisa direta. ${ }^{10}$

Quanto ao Atlas Lingüístico da Paraíba (ALPB), segundo Aragão (2005), os inquiridores contaram com uma preparação intensa, com a realização por alguns deles de cursos na França e Espanha. O projeto inicial data de 1974, mas efetivado somente em 1979, com o início da pesquisa direta em 25 municípios bases. O quadro abaixo permite visualizar a atuação da equipe de inquiridores.

\begin{tabular}{|l|l|l|}
\hline INQUIRIDORES & PONTOS & T \\
\hline $\begin{array}{l}\text { Cleusa Palmeira Bezerra de } \\
\text { Menezes }\end{array}$ & Todos os pontos & 25 \\
\hline Maria Betânia Leite Lins & $\begin{array}{l}1,2,3,4,5,6,7,8,9,11,12,13,14,17,18, \\
19,20,21,23,25 .\end{array}$ & 20 \\
\hline $\begin{array}{l}\text { Maria da Penha Nascimento de } \\
\text { Andrade }\end{array}$ & $1,5,6,8,9,10,14,15,16,22,24$. & 11 \\
\hline Maria do Socorro Aragão & $1,4,7,17,20,22,24$. & 7 \\
\hline Egéria Celeste Silva da Silveira & $1,2,4,6,8,11,12$. & 7 \\
\hline Kátia Helena Pessoa & $4,5,6,9,14,15,16$. & 7 \\
\hline
\end{tabular}

Fonte: ALPB (ARAGÃO; MENEZES: 1984)

Quadro 4 - Inquiridores do ALPB

Conforme o Quadro 4, a maior atuação foi de Menezes, em todos os pontos, e de Lins em $80 \%$ deles.

${ }^{10}$ Ferreira e Cardoso (1994), porém, apresentam algumas ressalvas acerca do uso dessa modalidade de pesquisa: a) perda de controle por parte do investigador sobre a compreensão das questões por parte do informante; b) dificuldades de interpretação dos dados por parte do pesquisador; c) simplificação de informações em nível fonético, que conduzem os resultados; d) impossibilidade de serem sanadas dúvidas existentes no questionário e das próprias respostas dadas. 
Cronologicamente, o Atlas Lingüistico do Paraná (ALPR) foi o quinto atlas publicado no Brasil e o primeiro como tese de doutorado. A coleta foi iniciada em 1985 e finalizada em 1990. Inicialmente, a autora pretendia preparar uma equipe de alunos de Letras para a realização dos inquéritos, porém, o alto custo financeiro da obra fez a autora abandonar a ideia e realizar a maioria das entrevistas.

\begin{tabular}{|l|l|l|l|}
\hline \multirow{2}{*}{ INQUIRIDORES } & \multicolumn{2}{|l|}{ INQUÉRITOS } & T \\
\cline { 2 - 4 } & Feminino & Masculino & \\
\hline Vanderci de A. & $11,02,03,04,06,07,08,09$, & $02,03,05,07,10,11,12,13$, & 96 \\
Aguilera & $11,15,16,17,18,19,21,25$, & $14,15,16,17,20,21,22,23$, & \\
& $26,27,29,32,33,34,35,36$, & $24,25,27,28,30,31,32,34$, & \\
& $37,39,40,43,44,45,46,47$, & $36,37,38,39,40,41,42,44$, & \\
& $48,49,52,53,54,55,56,57$, & $45,46,48$, & \\
& $58,59,60,61,64,65$ & $49,50,51,53,54,55,56,57$, & \\
\hline Elaine C. Fabris & $12,13,22,23,24,31,38,41$, & $58,59,60,61,62,63,64$. & \\
& 42,50 & & 16 \\
\hline Alunos de Letras & $05,10,14,28,30$ & $01,04,29$, & 8 \\
\hline Ivone A. de Lima & $51,62,63$, & $08,19,35$, & 6 \\
\hline Rita C. Paulino & & $06,09,18,20$ & 4 \\
\hline
\end{tabular}

Fonte: ALPR - Apresentação (AGUILERA, 1990)

Quadro 5 - Inquiridores do ALPR

Estipulou-se o número total de localidades em $65,{ }^{11}$ sendo inquiridos dois informantes por localidade. Além da autora, participaram do trabalho quatro inquiridoras, que realizaram de quatro a sete entrevistas. Por se tratar de trabalho de doutorado, a autora optou por selecionar todos os informantes e fazer pelo menos um inquérito em cada ponto.

Na sequência, em 1980, foi criado um projeto com o objetivo de fazer um atlas linguístico do Rio Grande do Sul. Os procedimentos metodológicos foram definidos em 1982 quando

${ }^{11}$ Das quais 24 constam da relação de Nascentes (1958, p. 21). 
se decidiu ampliar a área de abrangência para toda a região sul do país.

Sob a coordenação de Walter Koch, em 1987, formaram-se equipes com pesquisadores das Universidades Federais do Rio Grande do Sul, de Santa Catarina e do Paraná. O Atlas LingüisticoEtnográfico da Região Sul (ALERS), conta com uma rede composta por 275 localidades distribuídas da seguinte forma: Paraná: 100 pontos, Santa Catarina: 80 pontos e Rio Grande do Sul: 95 pontos, o que daria uma média de 22, 9 inquéritos por pesquisador.

No Quadro 6, indicam-se os inquiridores e a produtividade de cada um.

\begin{tabular}{|l|l|c|}
\hline $\begin{array}{l}\text { INQUIRIDORES } \\
\text { PARANÁ }\end{array}$ & PONTOS & T \\
\hline Basilio Agostini (BA) & $074,091,093,094,100,122,144,148,155,171,177$ & \\
& $179,185,190,192,193,197,198,201,202,203,207$ & \\
& $213,214,217,218,219,220,223,224,225,238,240$ & 51 \\
& $241,246,250,251,255,261,262,263,264,271,277$ & \\
& $278,281,283,284,290,291,296$. & \\
\hline $\begin{array}{l}\text { José Luiz da Veiga Mercer } \\
\text { JLM) }\end{array}$ & $057,089,126,158,186,194,206,210,211,212$, & 16 \\
\hline $\begin{array}{l}\text { Vanderci de A. Aguilera } \\
\text { (VAA) }\end{array}$ & $\begin{array}{l}029,222,227,236,258,293 . \\
205\end{array}$ & 11 \\
\hline Catarina Rodrigues (CR) & $005,011,016,025,053,055,056,064,160,167,107,114,118,132,135$, & \multirow{2}{*}{13} \\
\hline Alunos Bolsistas & $141,150,152$. & 8 \\
\hline Ismael Pontes (IP) & $142,151,209,235,247,287,176,172$. & 1 \\
\hline
\end{tabular}

\begin{tabular}{|l|l|c|}
\hline $\begin{array}{l}\text { INQUIRIDORES } \\
\text { SANTA CATARINA }\end{array}$ & PONTOS & T \\
\hline Hilda Gomes Vieira (HV) & $\begin{array}{l}477,478,480,481,485,548,550,551,555,566, \\
569,572,574,581,582,584 .\end{array}$ & 16 \\
\hline $\begin{array}{l}\text { Felício Wessling Margotti } \\
\text { (FM) }\end{array}$ & $470,471,472,473,477,485,548,555,587,593$. & 10 \\
\hline $\begin{array}{l}\text { Maria Carolina G. Kehrig } \\
\text { (MGK) }\end{array}$ & $548,555,582$. & 3 \\
\hline $\begin{array}{l}\text { Oswaldo Antônio } \\
\text { Furlan(OF) }\end{array}$ & $\begin{array}{l}401,403,405,406,409,413,415,422,424,426, \\
429,433,434,435,438,439,441,447,448,452, \\
459,459,464,467,475,486,488,489,490,491, \\
\\
492,495,496,497,501,504,509,511,512,514,\end{array}$ & 61 \\
& $\begin{array}{l}516,517,523,529,536,537,541,545,548,552, \\
555,559,561,562,564,565,589,593,594,595, \\
596 .\end{array}$ & \\
\hline
\end{tabular}




\begin{tabular}{|l|l|c|}
\hline $\begin{array}{l}\text { INQUIRIDORES RIO } \\
\text { GRANDE DO SUL }\end{array}$ & PONTOS & T \\
\hline Walter Koch (WK) & $\begin{array}{l}602,611,613,615,627,629,644,676,708,742, \\
746,752,759,769,777,781,791,805,818,826,\end{array}$ & 30 \\
& $827,828,832,833,834,838,839,840,482,844$. & \\
\hline $\begin{array}{l}\text { Mário Silfredo Klassmann } \\
\text { (MK) }\end{array}$ & $\begin{array}{l}659,661,662,677,679,682,685,686,706,707, \\
740,743,745,754,782,783,784,785,787,789, \\
792,794,808,809,811,817,823,824,843 .\end{array}$ & 29 \\
\hline $\begin{array}{l}\text { Cléo Vilson Altenhofen } \\
\text { (CA) }\end{array}$ & $\begin{array}{l}648,671,684,691,698,701,703,713,714,720, \\
762,772,773,786,788,790,796,820,822 .\end{array}$ & 19 \\
\hline Basílio Agostini (BA) & $619,643,645,647,648,651,709,728$. & 8 \\
\hline $\begin{array}{l}\text { José Luiz da Veiga Mercer } \\
\text { (JLM) }\end{array}$ & $621,639,716$. & 3 \\
\hline Alunos Bolsistas & $\begin{array}{l}817,714,820,722,735,736,838,684,817,722, \\
736,711 .\end{array}$ & 12 \\
\hline
\end{tabular}

Fonte: ALERS Volume I (KOCH; KLASSMANN; ALTENHOFEN, 2002, p. 59)

\section{Quadro 6 - Inquiridores do ALERS}

Pelo Quadro 6, verifica-se que o ALERS preparou uma equipe relativamente grande, compatível com o número elevado de pontos e de informantes. São onze pesquisadores que fizeram entre 10 e 60 entrevistas. O interessante é observar o aproveitamento de alunos bolsistas do CNPq, ou da própria IES de origem, em Iniciação Científica, para realizar a coleta in loco. Esse procedimento tem um valor positivo na continuidade da Dialetologia e da Geolionguística no Brasil pela formação de novos pesquisadores, rumo à tão esperada consciência dialetológica de que falavam os pioneiros dessa área, ainda nos idos da metade do século XX. Outro dado é que alguns pesquisadores saíram dos limites de seus Estados de origem para atuar em outro, como Mercer e Basílio, que além dos inquéritos no interior do Paraná, também atuaram em localidades do Rio Grande do Sul.

Em 2004, foi publicado o Atlas Lingüistico Sonoro do Pará (ALiSPA), o primeiro no gênero. Trata-se de um trabalho de cunho inovador no Brasil, onde são utilizados recursos multimídias, que permitem ouvir a fala dos informantes de cada localidade, ver o espectrograma e a transcrição fonética de cada resposta. Quanto aos investigadores de campo, a equipe compunha-se de três 
coordenadores da zona urbana e um da zona rural (RAZKY, 2005, p. 214).

Vinculado ao Projeto Atlas Linguístico do Pará (ALiPA), a coleta dos dados foi feita durante o ano de 2001 junto a 42 informantes, divididos em 10 localidades pertencentes às seis mesorregiões do Estado, somando um banco de dados de 420 arquivos.

O ALiSPA, além de trazer inovações na apresentação dos resultados, é o primeiro atlas pluridimensional brasileiro publicado, cuja metodologia foi baseada no Projeto Atlas Linguistico do BrasilALIB. Em cada localidade foram inquiridos quatro informantes, selecionados com base nas variáveis sociais sexo e faixa etária. $\mathrm{O}$ Quadro 7 apresenta a equipe de inquiridores.

\begin{tabular}{|l|l|l|l||}
\hline CIDADE & INQ. PRINCIPAL & INQ. AUXILIAR 1 & $\begin{array}{l}\text { INQ. AUXILIAR } \\
2\end{array}$ \\
\hline Soure & Alcides F. de Lima & Abdelhak Razky & Arlon Martins \\
\hline Bragança & Alcides F. de Lima & Abdelhak Razky & Arlon Martins \\
\hline Altamira & Alcides F. de Lima & Raquel Lopes & \\
\hline Jacareacanga & Alcides F. de Lima & Raquel Lopes & \\
\hline Marabá & Marilucia Oliveira & Adriana Feitosa & \\
\hline Òbidos & Alcides F. de Lima & Arlon Martins & \\
\hline Almerim & Alcides F. de Lima & Arlon Martins & \\
\hline Belém & $\begin{array}{l}\text { Alcides F. de Lima e } \\
\text { Marilucia Oliveira }\end{array}$ & Arlon Martins & Abdelhak Razky \\
\hline
\end{tabular}

Fonte: Dados fornecidos via e-mail pelo coordenador do Projeto ALiSPA, Dr. Abdelhak Razky, em 12/08/2006.

Quadro 7 - Inquiridores do ALISPA

Cada entrevista foi realizada por um inquiridor principal e, pelo menos, por um auxiliar. Outro fato que deve ser destacado refere-se ao dialetólogo responsável pela pesquisa, o professor Abdelhak Razky, que coordenou todo o projeto, mas, como marroquino falante do português, considerou mais adequado que os inquéritos fossem realizados por falantes nativos do português.

$\mathrm{O}$ Atlas Lingḯstico do Amazonas (ALAM) foi elaborado como tese de doutorado de Maria Luiza de Carvalho Cruz, defendida na Universidade Federal do Rio de Janeiro. Para a coleta, Cruz passou 
três meses no interior do Amazonas fazendo a recolha dos dados. Por se tratar de trabalho de doutorado, Cruz realizou todos os inquéritos, isto é, investigou os 54 informantes distribuídos pelos nove pontos do interior do Amazonas. A autora também inovou nos procedimentos metodológicos, entrevistando seis informantes por localidade, distribuídos por três faixas etárias: um homem e uma mulher em cada uma das faixas.

Tem-se, como obra mais recente, o Atlas Lingüistico do Mato Grosso do Sul (ALMS), publicado em 2007. ${ }^{12}$ Segundo Oliveira (2007, p. 13), organizador do Atlas, foram longos 12 anos de coleta de dados e três diferentes versões do projeto. A rede de pontos foi composta por 32 localidades, em cada uma das quais foram inquiridos quatro informantes, somando 128 entrevistas divididas entre 18 inquiridores. $\mathrm{O}$ Atlas não fornece dados referentes às localidades em que cada entrevistador atuou, mas os números demonstram uma média de 7,1 entrevistas por pesquisador. Os inquiridores são:

\begin{tabular}{|l|l|l|}
\hline \multicolumn{3}{|l|}{ INQUIRIDORES } \\
\hline Ana Maria P. P. de Oliveira & Aparecida N. Isquerdo & Auri Claudionei M. Frubel \\
\hline Carla Regina de Souza & Carlos André da Silva & Claudete C. de Souza \\
\hline Cristiane N. Arakaki & Débora Pereira Simões & Deisy Costa da Silva \\
\hline Dercir Pedro de Oliveira & Elma C. Scarabelli & Karla G. Guimarães \\
\hline Maiara Moreira Ramiro & Paula Renata C. de Souza & Regiane C. P. Reis \\
\hline Renata Forte C. Sauer & Sânia F. Fernandes & Valéria Faria Cardoso \\
\hline
\end{tabular}

Fonte: ALMS, 2007, p. 15

Quadro 8 - Inquiridores do ALMS

\footnotetext{
${ }^{12} \mathrm{Um}$ fato que vale a pena ser destacado refere-se aos financiamentos da pesquisa, pois as três versões do projeto receberam financiamento para tal finalidade. Oliveira dá a notícia de que, inclusive, um veículo com tração nas quatro rodas foi fornecido ao projeto, pois, para enfrentar o solo pantaneiro havia a necessidade de um veículo que suportasse tais condições.
} 
A exposição feita sobre as equipes dos atlas (estaduais e regional) publicados permite traçar uma síntese sobre as características comuns e específicas:

(i) Com exceção do ALAM, os demais atlas contaram sistematicamente com mais de um pesquisador de campo; (ii) Nos atlas com mais de um investigador, verifica-se que a atuação de cada um não é homogênea, havendo aqueles que realizaram $50 \%$ ou mais dos inquéritos, ao contrário de outros com produtividade mínima;

(iii) Alguns atlas mantiveram a presença do inquiridor auxiliar, o que tem se mostrado bastante favorável ao bom rendimento da coleta de dados.

Observa-se, pois, que o método é bastante flexível quando se trata de definir o número de investigadores de campo, decisão que está vinculada às condições do Projeto: preparação da equipe, recursos financeiros suficientes, disponibilidade de tempo dos investigadores.

\section{A equipe de investigadores do Atlas linguístico do Brasil} (ALiB)

Como resultado das experiências dos atlas e do desejo de elaborar o tão sonhado atlas nacional, reúne-se em novembro de 1996, na Universidade Federal da Bahia (UFBA), a maioria dos autores de atlas linguísticos estaduais do Brasil, por ocasião do Seminário Caminhos e Perspectivas para a Geolingüística quando se efetiva o lançamento do Projeto Atlas Linguístico do Brasil - ALiB.

Por se tratar de um empreendimento de grande amplitude - rede de 250 pontos de inquéritos e universo de 1.100 informantes - formaram-se núcleos regionais presididos por um Comitê Nacional, com sede na UFBA. A cada núcleo regional foi atribuída a responsabilidade de coletar os dados em determinado número de Estados, além de armazenar, copiar em CD e transcrever grafemática e foneticamente esses dados para remetê-los ao Comitê.

Assim como nos demais atlas, a questão do inquiridor foi amplamente discutida, levando-se em conta que o ideal em uma 
pesquisa dialetológica é um número mínimo de entrevistadores para que se mantenha a homogeneidade da pesquisa. $\mathrm{Na}$ impossibilidade de constituir uma equipe menor, Ferreira e Cardoso (1994) recomendam a preparação da equipe seguindo as seguintes etapas: (a) discussão conjunta do questionário a ser aplicado; (b) audição de inquéritos de diferentes tipos e regiões; (c) aplicação de questionários experimentais.

De acordo com a ata das primeiras reuniões do Comitê, decidiu-se que cada regional contaria com apenas dois inquiridores. Pouco a pouco, chegou-se à conclusão de que o grande número de pontos atribuídos a cada regional ${ }^{13} \mathrm{e}$ a ausência de um financiamento global inviabilizavam tal medida. Assim, já na ata da reunião de 6 de outubro de 1999 sugeriu-se que o número total de inquiridores, devidamente preparados, não excedesse a 20 , que hoje foi expandido para 30 pesquisadores em todo o Brasil.

Cada pesquisador, para ser habilitado como inquiridor do $\mathrm{ALiB}$, deve realizar um inquérito experimental e submetê-lo ao Comitê Nacional, que avalia o desempenho do candidato e aprovao ou não. Recomenda-se, também, que o aspirante a inquiridor tenha realizado pelo menos duas transcrições grafemáticas e fonéticas de entrevistas do Projeto, para se familiarizar com o questionário, com as demais fases da pesquisa geolinguística e com o estilo de diferentes inquiridores.

Ao longo dos 12 anos de caminhada, vários procedimentos adotados inicialmente tiveram que ser revistos devido às dificuldades encontradas, pois a realidade demonstrava que o ideal não coincidia com o real. Nota-se, hoje, que, apesar das dificuldades de várias naturezas, o saldo do Projeto é extremamente positivo,

${ }^{13}$ A título de ilustração pode-se citar a Regional Paraná, que ficou responsável pela coleta dos dados nos Estados de Amapá, São Paulo e Paraná, totalizando 57 pontos e 240 entrevistas. Seria praticamente inviável contar com apenas dois inquiridores para realizar todos os inquéritos. 
uma vez que o ALiB inaugura uma nova fase na Dialetologia brasileira. A tão almejada mentalidade dialetológica pôde ser criada e está sendo alimentada nas diversas instituições de ensino superior, e tem rendido safras de bons trabalhos científicos na área cujo objeto é a língua falada e estratificada, colhida, sistematicamente, nos mais diversos recantos do Brasil e, assim, oferecendo um vasto material para a descrição do Português brasileiro.

\section{Considerações finais}

Essa pesquisa teve como propósito fazer um balanço dos procedimentos metodológicos adotados pelos atlas linguísticos até então concluídos e ou publicados no Brasil, em particular no que se refere ao inquiridor de campo ou à equipe de inquiridores. Com este panorama, os resultados indicaram que, de acordo com a natureza do trabalho, pode-se optar pelo inquiridor único, no caso de dissertações e teses, mas a maioria volta-se para a formação de equipes de investigadores de campo para que, dada à extensão territorial abrangida, o montante dos recursos financeiros obtidos e o tempo disponível de cada pesquisador, se possa levar a termo um trabalho de tal envergadura.

Apesar do rigoroso planejamento, verifica-se que a pesquisa de campo sempre oferece surpresa aos seus executores. São fundamentais as palavras de Silva Neto (1957, p. 34): "É preciso lembrar, contudo, que as pesquisas de campo são a negação de todo e qualquer esquematismo. Cada região tem os seus problemas próprios, que muitas vezes não podem ser resolvidos senão no terreno."

O ideal é que, em todas as localidades a serem investigadas, seja realizada uma sondagem preliminar e, preferencialmente, o coordenador regional esteja presente, pois só ele pode tomar decisões que outros pesquisadores hesitariam em assumir, mesmo porque cada inquérito é um momento único entre pesquisador e informante quando até os mais experientes se deparam com situações inusitadas. 
Um dos fatos mais mencionados pelos pesquisadores de campo tem sido o da contradição que vivenciam: ao lado de uma pesquisa objetiva e racional que têm que executar, convivem com outro ser humano, mesmo que por poucas horas, mas que se sente valorizado naquele momento de interlocução. Por isso, por mais objetivo que se pretenda ser, ninguém foge do contato humano.

Não foi diferente com Lindley Cintra (1995, p. 9), inquiridor do Atlas Lingüistico de Portugal, que assim inicia sua obra, mostrando que faz parte do ser humano, mesmo em situação de pesquisa, se deixar envolver pelo lado emocional:

Penso freqüentemente na minha experiência dialetológica e encontro nela motivos para prosseguir - e animar outros a prosseguir. Recordo paisagens e, enquadrados nelas, homens e mulheres. Diversos como os cenários em que se situavam, contavam-me histórias, diversas também. Ao fim de dois ou três dias sentíamo-nos por vezes verdadeiros amigos, quase irmãos. Eu não tinha podido dar-lhes senão um pouco de atenção, de simpatia. Eles tinham me dado uma lição magnífica, decisiva para o meu modo de sentir e de pensar a partir daquele momento. Atrás dos falares que tinha vindo estudar, era toda uma humanidade humilde, mas digna, vivendo intensamente os sentimentos simples, lutando corajosamente pela sobrevivência, com que a dialetologia me tinha posto em contato. Se mais nada, no vasto terreno da linguística, conservasse um dia interesse para mim, creio que esta experiência seria só por si suficiente para me obrigar a reconhecer e afirmar que vale a pena o ramo de estudos para que a vida me conduziu.

\section{Referências}

AGUILERA, Vanderci de Andrade (Org.). A geolingüística no Brasil - trilhas seguidas, caminhos a percorrer. Londrina: Eduel, 2005. 
(Org.). A geolingüística no Brasil - caminhos e perspectivas. Londrina: Eduel, 1998.

. Atlas Lingüístico do Paraná. Curitiba: Imprensa Oficial do Estado, 1994.

ALTINO, Fabiane Cristina. Atlas Lingüístico do Paraná-ALPR II. 2007. Tese (Doutorado em Estudos da Linguagem) Universidade Estadual de Londrina, Londrina. $3 \mathrm{v}$.

ALVAR, Manuel. Estudios de Geografia Lingüística. Madrid: Editorial Paraninfo, 1991.

. Estruturalismo, Geografia Lingüística y Dialectologia Atual. Madrid: Gredos, 1969.

ARAGÃO, Maria do Socorro Silva de; MENEZES, Cleuza Palmeira Bezerra de. Atlas Lingüístico da Paraíba. Brasília: Universidade Federal da Paraíba; CNPq, 1984. 2.- v.

ATLAS LINGÜÍSTICO SONORO DO PARÁ. Apresentação. Disponível em: <http://www.ufpa.br/alipa/apresentacao.htm>. Acesso em: 12 ago. 2006.

BRAND ÃO, Silvia Figueiredo. A geografia lingüística no Brasil. Curitiba: Ática, 1991.

CARDOSO, Suzana Alice Marcelino. Atlas lingüístico de Sergipe II. Rio de Janeiro: UFRJ. 2002. Tese (Doutorado em Letras) Universidade Federal do Rio de Janeiro, Rio de Janeiro.

; FERREIRA, Carlota. A dialetologia no Brasil. São Paulo: Contexto, 1994.

CINTRA, Luís Felipe Lindley. Estudos da Dialectologia Portuguesa. Lisboa: Livraria Sá da Costa, 1995.

CRUZ, Maria Luiza. Atlas lingüístico do Amazonas - ALAM. 2004. Tese (Doutorado em Letras) Universidade Federal do Rio de Janeiro, Rio de Janeiro. 2 v. 
FERREIRA, Carlota; FREITAS, Judith; MOTA, Jacyra; ANDRADE, Nádia; CARDOSO, Suzana; ROLLEMBERG, Vera; ROSSI, Nélson. Atlas Lingüístico de Sergipe. Salvador: Universidade Federal da Bahia; Fundação Estadual de Cultura do Sergipe, 1987.

KOCH, Walter; KLASSMANN, Mário Silfredo; ALTENHOFEN, Cléo Vílson (Orgs.) Atlas lingüístico-etnográfico da região Sul do Brasil. Porto Alegre/Florianópolis/Curitiba: Ed.UFRGS/ Ed.UFSC/Ed.UFPR, 2002. 2 v. Disponível em: <http:// www.alers.ufsc.br/projeto_alers.htm>.

MOUTON, Pilar García. Dialetologia y Geografía Lingüística. In: ALVAR, M. (Dir.) Manual de Dialectología Hispânica. El español de España. Barcelona: Ariel, 1996. p. 63-77.

NASCENTES, Antenor. Bases para a elaboração do Atlas Lingüístico do Brasil. v. II. Ministério da Educação e da Cultura/ Casa de Rui Barbosa, 1961.

Bases para a elaboração do Atlas Lingüístico do Brasil. v. I. Ministério da Educação e da Cultura/Casa de Rui Barbosa, 1958.

O PROJETO ALERS. Origem, procedimentos e métodos. Disponível em: < http://www.alers.ufsc.br/projeto_alers.htm>. Acesso em: 13 abr. 2009.

OLIVEIRA, Dercir Pedro de (Org.). Atlas Lingüístico do Mato Grosso do Sul. Campo Grande: UFMS, 2007.

PROJETO ATLAS LINGUÍSTICO DO BRASIL. Ata da V Reunião do Comitê Nacional do Projeto ALiB, realizada em Salvador nos dias 6, 8, 9 e 10 de setembro de 1999. (fotocopiada circulação restrita).

Ata da IV Reunião do Comitê Nacional do Projeto ALiB, realizada em Florianópolis no dia 27 de fevereiro de 1999. (fotocopiada - circulação restrita). 
RAZKY, Abdelhak. Inquiridores [mensagem pessoal]. Mensagem recebida por<greize_silva@yahoo.com.br> em 13 ago. 2006.

Atlas lingüístico sonoro do Pará: uma nova perspectiva para a organização de corpus geolingüístico. In: AGUILERA, Vanderci de Andrade (Org.). A geolingüística no Brasil - trilhas seguidas, caminhos a percorrer. Londrina: Eduel, 2005. p. 209227.

RIBEIRO, José; ZÁGARI, Mário Roberto Lobuglio; PASSINI, José; GAIO, Antonio Pereira. Esboço de um atlas lingüístico de Minas Gerais. v. 1. Rio de Janeiro: Fundação Casa Rui Barbosa/ Universidade Federal de Juiz de Fora, 1977.

ROSSI, Nélson; FERREIRA, Carlota; ISENSEE, Dinah. Atlas Prévio dos Falares Baianos. Rio de Janeiro: Instituto Nacional do Livro/Ministério da Educação e Cultura, 1963.

SILVA NETO, Serafim da. Guia para estudos dialectológicos. Belém: Instituto Nacional de Pesquisas da Amazônia, 1957.

VENY, Joan. Introducción a la dialectología catalana. Barcelona: Biblioteca Universitaria, 1986.

WOUK, Miguel. Estudo etnográfico-lingüístico da comunidade ucraína de Dorizon. Curitiba: Projeto, 1981. 